\title{
On Evaluation of the Theoretical Soundness of Critical Discourse Analysis
}

\author{
Yu Fang \\ Foreign Language Department, Qingdao University of Science and Technology, Qingdao 266001, China \\ Email: kristyfy@163.com
}

\begin{abstract}
Critical discourse analysis (CDA) is an interdisciplinary approach to the study of texts, which views language as a form of social practice. As a new trend of discourse analysis, CDA has been more recently announced internationally. This paper elaborates on the theoretical framework of CDA and highlights the evaluation of the theoretical soundness of it from two aspects --- usefulness and criticism.
\end{abstract}

Index Terms - critical discourse analysis (CDA), theoretical soundness, ideology

\section{INTRODUCTION}

On 16 January 2006, Iran suspended CNN's accreditation after an employee of this news service misquoted President Mahmud Ahmadinejad. The whole story was that during its simultaneous translation of a presidential news conference on 14 January, CNN quoted Ahmadinejad as saying: "The use of nuclear weapons is Iran's right." What Ahmadinejad actually said was: "The use of nuclear energy and technology is Iran's right." The Iranian authorities accused the broadcaster of deliberately mistranslating Ahmadinejad's statement. Hence, the Culture Ministry of Iran announced that no CNN staffers would be allowed into the country until further notice. This event illustrates what the theory of critical discourse analysis (henceforth CDA) advocates well: everybody may hold a political attitude to language in use and thereby reveal ideology, power and dominance hidden in language.

Critical discourse analysis, a new trend of discourse analysis, has established itself internationally over the past twenty years or so. The distinctiveness of the theory lies not so much in the analytic techniques it employs as in its attempt to locate discourse within a particular conception of society, and its adoption of a thoroughly "critical" attitude towards that society. CDA assumes that in producing knowledge of society critical research reveals what is obscured by ideology, such ideology being seen as pervasive and as playing an essential role in preserving the status quo and that by acting on the basis of critical theory we can change the world for the better. Moreover, the change produced will be fundamental in character, such as to eradicate oppression and emancipate all human beings. But it's a pity that CDA was introduced into China very late--- no related papers appeared until 1995--- and even up to now relatively few language scholars know about it. Thereby, the paper firstly intends to make an general introduction to CDA. However, the chief purpose of it is to evaluate the theoretical soundness of this theory.

\section{THEORY OF CRITICAL DISCOURSE ANALYSIS}

Critical discourse analysis mainly analyses social interactions in a way which focuses upon their linguistic elements, and which sets out to show up their generally hidden determinants in the system of social relationships, as well as hidden effects they may have upon that system (Fairclough, 1989). Though announced more recently, the theory has attracted a great deal of interest internationally, "Critical discourse analysis ... has established itself internationally over the past twenty years or so as a field of cross-disciplinary teaching and research which has been widely drawn upon in the social sciences and humanities (for example, in sociology, geography, history and media studies), and has inspired critical language teaching at various levels and in various domains"(Chouliaraki and Fairclough, 1999, p. 1).

$\mathrm{CDA}$ is defined as an interdisciplinary approach to the study of texts, which views "language as a form of social practice" (Fairclough, 1989, p. 20). Fairclough and Wodak (1997) summarize the main tenets of CDA as follows: (1) CDA addresses social problems. (2) Power relations are discursive. (3) Discourse constitutes society and culture. (4) Discourse does ideological work. (5) Discourse is historical. (6) The link between text and society is mediated. (7) Discourse analysis is interpretative and explanatory. (8) Discourse is a form of social action.

CDA theorists have woken up to the fact that the approach requires true multidisciplinarity, and an account of intricate relationships between text, talk, social cognition, power, society and culture. And they are open about their goals: exposing hegemony, demonstrating "hidden" ideological processes, and equipping people in critical language awareness, the educational application of critical discourse analysis (Tyrahitt-Drake, 1999). Hence they commit themselves to solving the persistent problems of oppression, injustice and inequality that demand urgent attention, such as discrimination, sexism, superiority - inferiority distinction, etc. Correspondingly CDA sets its critical targets to the power elites that enact, sustain, legitimate, condone or ignore social inequality and injustice (van Dijk, 1993).

The major issues which the approach of CDA deals with center on the relations between discourse, society, ideology 
and power:

(1) Discourse and Society

In the viewpoint of CDA, there is an internal and dialectical relationship between language and society, not an external one. Firstly, language is a part of society. On the one hand, linguistic phenomena are social phenomena of a special sort. In this sense, whenever people speak or listen or write or read, they do so in ways which are determined socially and have social effects. On the other hand, social phenomena are (in part) linguistic phenomena, which implies that the language activity that goes on in social contexts (as all language activity does) is not merely a reflection or expression of social processes and practices, it is a part of those processes and practices.

(2) Discourse and Ideology

In the article Principles of Critical Discourse Analysis, Teun A. van Dijk (1993) claims that social cognition is the necessary theoretical (and empirical) "interface" between discourse and society as well as power and dominance, and that neglect of social cognition has been one of the major theoretical shortcomings of most work in discourse analysis. Socially shared representations of societal arrangements, groups and relations, as well as mental operations such as interpretation, thinking and arguing, inferencing and learning, among others, together define what we understand by social cognition. On the part of van Dijk, discourse, communication and (other) forms of action and interaction are monitored by social cognition. The same is true for understanding of social events or of social institutions and power relations.

Ideologies are the fundamental social cognitions that reflect the basic aims, interests and values of groups (van Dijk, 1993). For CDA, ideology refers to social forms and processes within which, and by means of which, symbolic forms circulate in the social world, and is seen as an important means of establishing and maintaining unequal power relations (Wodak, 2002).

(3) Discourse and Power

Power, control and dominance are the main issues CDA pays great importance to. Power involves control, namely by (members of) one group over (those of) other groups. Such control may pertain to action and cognition, that is, a powerful group may limit the freedom of action of others, but also influence their minds (van Dijk, 1993). It's viewed that modern and often more effective power is mostly cognitive and enacted by persuasion, dissimulation or manipulation, among other strategic ways to change the mind of others in one's own interests which is essentially a function of text and talk. Hence, CDA also needs to focus on the discursive strategies that legitimate control, or otherwise "naturalize" the social order, and especially relations of inequality.

In an overview of the principles of critical discourse analysis, Van Dijk (1993) distinguishes three aspects of language power: "reproduction" which is the process by which elites exert their dominance through language; "resistance", which is the way the less powerful attempt to oppose the attempts by elites to dominate them; and "joint-production", which is when dominated groups are persuaded that dominance is "natural", or in some way legitimate.

\section{EVALUATION OF THE CDA THEORY}

\section{A. Usefulness of CDA}

From the principles mentioned above, the CDA theory does function in practice to some extent. But to what extent the theory is useful and feasible? The question needs to be discussed from these aspects: the original intention of CDA, applied registers and analytical tools. Different from the mainstream linguistics which puts focus on language proper, CDA sets language in use as its subject for investigation, so it advocates that the production of discourse is the result of the producer's intentionality, namely ideology. It cannot be denied that when a producer uses a language, he/she has to make some choices, the process of which involves the producer's intentionality, preference and habit, etc. CDA theorists have realized the importance of intentionality in discourse and have given it unprecedented emphasis.

This aspect is found to be more illustrative for some applied registers of the CDA theory, esp. that the usefulness and feasibility of CDA is clear in political discourse, news reports covering politics, sexism, racism, diplomacy and public discourse and the like. Taiwan's case is very illustrative. In the presidential election, both the pan-blue and pan-green camps find fault with each other and thus are careful in their choice of words to cover or blur their true intention so as to advance their advantage in election. Moreover, Chen Shuibian's speeches show the point that his intention always remains the same no matter what and how he says, that is, remaining in power through advocating the independence of Taiwan. In such sense, the theory of CDA provides people a new mode of thinking, which helps not merely to get information from the literal meaning, but read between the lines.

As far as the analytical tools of CDA are concerned, CDA provides lists of formal linguistic features which are likely to be ideologically significant, and such features are cited in analyses. It can be understood that linguistic devices do serve to the expression of the producer's ideology rhetorically with some perceived and the others hidden. In fact, for politicians' part, the deeper their ideology is hidden, the more successful their discourses are. Thus, the power elites always try to use various linguistic devices to cover their intentionality so as to transfer their ideologies to the public unconsciously and realize their aims which is the so-called language hegemony.

For its positive part, CDA helps people to detect what the advantaged have to say but perhaps they are not willing to say out, so that when interpreting such discourses, people need to read between the lines to get the implication, which also means a sign for the judgement of the producer's attitude. Therefore, one of the theoretical significances of CDA is 
to put forward critical approaches in education, aiming at fostering people's critical language awareness (CLA) in communication.

\section{B. Criticism on CDA}

Firstly, the theory itself sounds self-contradictory and subjective to some extent. The idea that the relation between form and content is not arbitrary makes CDA practitioners insist that there are relations between language, power and ideology, and between how the world is represented in texts and how people think about the world so that the recipient should analyze the discourse critically to finally reveal the hidden ideology and hegemony in language. If so, CDA theory itself is the product of the ideologies of CDA theorists, i.e. the theory itself is rather subjective than objective, because analysts know perfect well at the outset just what political position they're going to find. Facts have testified that the textual interpretations of CDA are politically rather than linguistically motivated and that analysts find what they expect to find, whether absences or presences (M. Stubbs, 1997).

Secondly, the theory is overambitious of the task that it sets itself. It aims to achieve a very great deal more than other kinds of discourse analysis. Not only does it claim to offer an understanding of discursive processes, but also of society as a whole, of what is wrong with it, and of how it can and should be changed (M. Hammersley, 1997). However, the problem is that, take conversations between father and son as an example, even though the son realizes the domination and hegemony in his father's words, what should and would he do, to resist or to break his father's domination? Opposed to what CDA expects, overplay of communicative intentionality would lead to fussiness and oversensitivity and thus increases the burden of verbal communication, and runs the risk of violating the economic principle for language use. In this sense, CDA is not practical and feasible.

Thirdly, CDA is more ideologically or socially sound but not so much in linguistics; it's based on a bias in judgment rather than objective observation as well as on a philosophy of fight and mentality of deep distrust. CDA practitioners take it for granted that the producer of a discourse always tries to reinforce his position or ideology through discourse both in implicit and explicit ways. It reminds us of the period of the cultural revolution when Chinese people were cautioned never to forget class struggle and were told that whatever arise should be evaluated in terms of class struggle. We Chinese have long had such understanding; but the westerners think they are independent individuals who can have their own way of thinking and doing things, and often wary of erosion of their individuality, which could hardly be maintained if CDA advocates' way of cognition were adopted. Similarly, the way of expression criticized by CDA practitioners is perhaps the result of democratic movement, which has made the advantaged have more careful consideration in expression instead of in arbitrary or dictating manners. In addition, what is often taken for granted by every practitioner of discourse analysis is that in verbal communication participant has his or her own interest and habits to use words and has own interest to guard or promote. Everyone speaks to enhance not against his or her own benefits or right, it is a universal natural tendency rather than an ideological strategy. Nevertheless, like politics and economy, ideology is inevitable in any contemporary social phenomenon and no one would like to say something against his own interest even if it is a confession, so social advantage is always present in discourse. As a matter of fact, it would be very difficult and elaborate for one to entirely free himself from the influence of ideology; nor is it necessary.

Finally, we find that, apart from political discourse, public discourses and media news about sensitive topics, CDA theory does not work everywhere. In mass communication, CDA is nearly useless to news reports about science and technology, for language of science and technology always strives to be clear and objective. Though such analysis works in verbal advertisements, what's the practical use of critical discourse analysis? The audience would be disappointed and mock the advertiser if an ad were not attractive, for everybody knows that the purpose of advertisement is to attract consumer's eye to the product on sale and to allure consumer to buy with various verbal and visual means. In daily communication, neither is CDA meaningful. An example has been given in the second point. It's clear that the range of application of CDA has a strict limitation, hence it's viewed by the author that the notion of CDA should be defined in a more detailed way.

To conclude, in the author's opinion the CDA theory is closely related to registers rather than the attribute of linguistic forms. In particular, the overplay of political awareness greatly restricts its applicability within some registers.

\section{CONCLUSION}

Today, in fact, there must scarcely be an area of social research has not witnessed the emergence of a critical perspective. So does the discipline of discourse analysis. The "critical" attitude of CDA distinguishes it from the previous approaches and fills the field with vitality. Nevertheless, the merits and demerits of the theory should be dealt with correctly. The research done in the paper is to examine the theory and make a deeper understanding of it.

The CDA theory, more or less, misunderstands the various functions of linguistic forms as the attribute of linguistic forms. It's testified that CDA is not the natural or mainstream way of thinking. When over applied, it may become a criticism on the fundamental functions of language as a whole, and anyway, freedom of expression and diversity of expression shall be endangered by widespread application of CDA, so is the freedom of interpretation, for only power, ideology is taken into consideration. On the other hand, in a time of cultural and speech hegemony, it's necessary for the common people to develop critical language awareness to guard themselves against suppression in various forms, 
including linguistic forms. In such sense, CDA can play an important role to serve such purpose.

\section{REFERENCES}

[1] Chouliaraki, L. \& Fairclough, N. (1999). Discourse in Later Modernity: Rethinking Critical Discourse Analysis. Edinburgh: Edinburgh University Press.

[2] Fairclough, N. (1989). Language and Power. London: Longman.

[3] Fairclough, N.\& Wodak. R. (1997). Critical Discourse Analysis. In Van Dijk (Eds), Discourse as Social Interaction (Vol. 2). London: Sage, 258 - 284.

[4] Hammersley, Martyn. (1997), On the Foundations of Critical Discourse Analysis. Language and Communication, 3, 237 - 248.

[5] Stubbs, M. (1997). Whorf's Children: Critical Comments on Critical Discourse Analysis. In Ann Ryan \& Alison Wray (Eds), Evolving Models of Language. Clevedon: Multilingual Matters, 100 - 116.

[6] Tyrwhitt-Drake, Hugh. (1999). Resisting the Discourse of CDA: Reopening a Hong Kong Case Study. Journal of Pragmatics, 31, $1081-1088$.

[7] Van Dijk, Teun A. (1993). Principles of Critical Discourse Analysis. Discourse and Society, 2, 249 - 283.

[8] Wodak, Ruth. (2002). Aspects of CDA. Zeitschrift für Angewandte Linguistik, 36, 5 - 31.

Yu Fang was born in Qufu, Shandong Province, China in 1977. She received her M.A. degree in linguistics from Nanchang University, China in 2006.

She is currently a lecturer in the School of Foreign Language, Qingdao University of Science and Technology, Qingdao, China. Her research interests include Second Language Acquisition and Translation. 